\title{
Inhibition of apoptosis improves outcome in a model of congenital muscular dystrophy
}

\author{
Mahasweta Girgenrath, Janice A. Dominov, Christine A. Kostek, and Jeffrey Boone Miller
}

Neuromuscular Biology and Disease Group, Boston Biomedical Research Institute, Watertown, Massachusetts, USA.

\begin{abstract}
The most common form of human congenital muscular dystrophy (CMD) is caused by mutations in the laminin- $\alpha 2$ gene. Loss of laminin- $\alpha 2$ function in this autosomal recessive type $1 \mathrm{~A}$ form of CMD results in neuromuscular dysfunction and, often, early death. Laminin- $\alpha 2$-deficient skeletal muscles in both humans and mice show signs of muscle cell death by apoptosis. To examine the significance of apoptosis in CMD1A pathogenesis, we determined whether pathogenesis in laminin- $\alpha 2$-deficient $\left(\right.$ Lama2 $\left.^{-/-}\right)$mice could be ameliorated by inhibiting apoptosis through either (a) inactivation of the proapoptosis protein Bax or (b) overexpression of the antiapoptosis protein Bcl-2 from a muscle-specific transgene. We found that both of these genetic interventions produced a several-fold increase in the lifespan of $\mathrm{Lama2}^{-/-}$mice. Bax inactivation also improved postnatal growth rate and myofiber histology and decreased fixed contractures of $\mathrm{Lama2}^{-/-}$mice. Thus, Bcl-2 family-mediated apoptosis contributes significantly to pathogenesis in the mouse model of CMD1A, and antiapoptosis therapy may be a possible route to amelioration of neuromuscular dysfunction due to laminin- $\alpha 2$ deficiency in humans.
\end{abstract}

\section{Introduction}

The most common form of human congenital muscular dystrophy (CMD) is caused by mutation of the human LAMA2 (mouse Lama2) gene that encodes laminin- $\alpha 2$ (1-3). Loss of laminin- $\alpha 2$ function in this autosomal recessive type $1 \mathrm{~A}$ form of CMD results in neuromuscular dysfunction and often early death. Multiple mutations have been found that lead to truncated gene products and loss of laminin- $\alpha 2$ protein $(2,3)$, with most of the mutations in exons $1-31$ of the 64 exons in the gene. Additional LAMA2 mutations, clustered in exons 58-64, produce partial laminin- $\alpha 2$ deficiency with a less severe clinical course (2). Partial laminin- $\alpha 2$ deficiency is also found in Fukuyama CMD, muscle-eye-brain disease, and Walker-Warburg syndrome, though these diseases are caused by mutations in genes other than LAMA2 (3).

Laminin- $\alpha 2$ is an extracellular protein with multiple-binding partners. In skeletal muscle, laminin- $\alpha 2$ associates with the additional laminin subunits $\beta 1$ and $\gamma 1$ to form the heterotrimeric laminin-2 complex. Heterotrimeric laminins that include laminin- $\alpha 2$ (e.g., $\alpha 2$, $\beta 1, \gamma 1)$, are termed merosins. Thus, CMD1A has also been termed merosin-deficient CMD. Laminin- $\alpha 2$ plays a key role in linking cellular and extracellular components. An extracellular binding partner of laminin- $\alpha 2$ is entactin/nidogen, which in turn binds to collagen IV. In addition, laminin- $\alpha 2$ has at least two membrane-associated binding partners in skeletal muscle: $\alpha$-dystroglycan and $\alpha 7$-integrin (2), each of which is complexed with additional proteins.

Inappropriate induction of apoptotic cell death in skeletal muscles and motor nerves is one possible mechanism by which loss of laminin- $\alpha 2$ leads to neuromuscular dysfunction. Indeed, laminin- $\alpha 2$-deficient skeletal muscles in both humans and mice show relatively abundant signs of muscle cell death by apoptosis (4-6). To examine the significance of apoptosis in CMD1A pathogenesis, we determined whether pathogenesis in laminin- $\alpha 2-$ defi-

Nonstandard abbreviations used: CMD, congenital muscular dystrophy. Conflict of interest: The authors have declared that no conflict of interest exists.

Citation for this article: J. Clin. Invest. 114:1635-1639 (2004).

doi:10.1172/JCI200422928. cient (Lama2 $2^{--}$) mice could be ameliorated by inhibiting apoptosis through either (a) inactivation of the proapoptosis protein Bax or (b) overexpression of the antiapoptosis protein $\mathrm{Bcl}-2$ from a muscle-specific transgene. We found that both of these genetic interventions produced a several-fold increase in the lifespan of Lama2 $2^{-/}$mice. Bax inactivation also improved postnatal growth rate and myofiber histology and decreased fixed contractures of Lama2 ${ }^{-/-}$mice. We conclude that Bcl-2 family-mediated apoptosis contributes significantly to pathogenesis in the mouse model of CMD1A. In addition, antiapoptosis therapy may be a possible route to amelioration of neuromuscular dysfunction due to laminin- $\alpha 2$ deficiency in humans.

\section{Results}

A large percentage of $\mathrm{Lama2}^{-/-}$mice die within the first 2 months of birth $(5,7)$. We found, however, that this early death was completely eliminated when the Lama2 ${ }^{-/-}$mice were made Bax-null by cross-breeding (Figure 1A). When not sacrificed earlier for histology, we found that all Lama2 ${ }^{-/-} \mathrm{Bax}^{-/-}$mice that lacked both laminin$\alpha 2$ and Bax survived for more than 120 days after birth $(n=10)$, whereas more than half of the Lama2 $2^{-/-} \mathrm{Bax}^{+/+}$mice that lacked laminin- $\alpha 2$ but had normal levels of Bax died within 60 days of birth. We also found an improvement in lifespan of Lama2 $2^{-/-}$mice that were $\mathrm{Bax}^{+/-}$heterozygotes and thus had reduced expression of Bax, though this improvement was modest compared with the complete elimination of early death seen in Lama2 $2^{-1-}$ mice that entirely lacked Bax (Figure 1A). We kept Lama2 ${ }^{-/-}$Bax ${ }^{-/-}$mice for up to 171 days prior to sacrifice for histological studies and never saw a spontaneous death during this period.

In addition to increasing lifespan, inactivation of Bax expression improved the growth of Lama2 $2^{-/-}$mice (Figure 1, B and C). Lama2 ${ }^{-/}$ Bax ${ }^{-1}$ mice gained weight more quickly and grew significantly larger than $\mathrm{Lama2}^{-/-} \mathrm{Bax}^{+/+}$mice; nonetheless, the Lama2 $2^{-/-} \mathrm{Bax}{ }^{-/-}$mice did not grow as quickly or to as large a size as healthy mice that had normal expression of laminin- $\alpha 2$. Although absence of Bax improved the growth of Lama2 $2^{-/-}$mice, the presence or absence of Bax did not affect the growth rate of normal Lama2 ${ }^{+/+}$mice (8). 

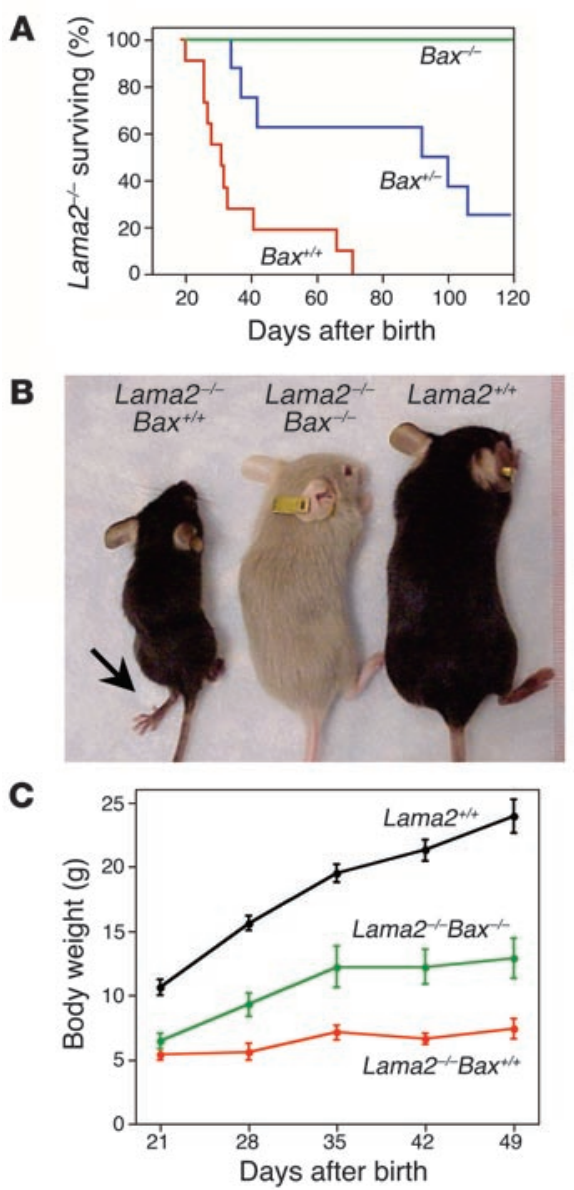

The lifespan of Lama2 $2^{-/-}$mice was also increased several-fold by transgenic overexpression of the antiapoptosis protein $\mathrm{Bcl}-2$ in skeletal muscle. To increase expression of Bcl-2 only in skeletal muscle, we produced a transgene in which an approximately $7-\mathrm{kb}$ fragment of the muscle-specific MyoD promoter was used to direct expression of human Bcl-2 (Figure 2A). Bcl-2 is not highly

\section{Figure 2}

(A) Diagram of the cDNA used to produce $p M y o D-h B c l-2$ transgenic mice in which an approximately 7-kb fragment of the mouse MyoD promoter was used to drive expression of full-length human $\mathrm{Bcl}-2$ (hBcl-2) cDNA. Arrows show locations of genotyping PCR primers. SV40, simian virus 40 splicing sequence. (B) Transgene expression is skeletal-muscle specific. As indicated, Ab's specific for transgenic human $\mathrm{Bcl}-2$ or endogenous mouse $\mathrm{Bcl}-2$ were used to probe Western blots of protein extracts made from tissues of wild-type or transgenic mice. Human Bcl-2 was expressed only in skeletal muscles (LM, leg muscles; $\mathrm{Di}$, diaphragm) of transgenic mice; it was not expressed in skeletal muscles of wild-type mice or in nonmuscle tissues (Kd, kidney; $\mathrm{Br}$, brain; $\mathrm{Ht}$, heart) of transgenic mice. The endogenous mouse $\mathrm{Bcl}-2$ was expressed in thymus (Th) and spleen (Sp) of wild-type mice, but was not detectable in skeletal muscles of either wild-type or transgenic mice or in heart and liver (Lv) of transgenic mice. (C) Myotubes formed in culture from myoblasts derived from 3-week-old $p M y o D-h B c l-2$ leg muscles were more resistant to cell death induced by $100 \mathrm{nM}$ staurosporine measured by propidium iodide (PI) permeability than those formed by wild-type myoblasts.

\section{Figure 1}

Inactivation of Bax eliminated early death and improved growth of laminin- $\alpha 2-$ deficient Lama2 $2^{-/-}$mice. (A) Survival curves for Lama2-/mice show that most $L a m a 2^{-/-} \mathrm{Bax}^{+/+}$mice died within 2 months of birth, whereas lifespan was modestly increased in heterozygous Lama2-/$\mathrm{Bax}^{+/-}$mice, and early death was completely eliminated in Lama2 ${ }^{-/-}$ Bax ${ }^{-1-}$ mice. (B) Pictured at 6 weeks after birth, a Lama2 ${ }^{-1-} \mathrm{Bax}^{-1-}$ mouse (center) was much larger than a Lama2 ${ }^{-/-} \mathrm{Bax}^{+/+}$mouse (left), though not so large as a wild-type $\mathrm{Lama2}^{+/+} \mathrm{Bax}^{+/+}$mouse (right). Contractures

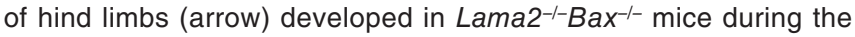
first 2-3 months of life but did not develop on Lama2 ${ }^{-1-B a x^{-/}}$or wildtype mice. (C) Growth curves show that the postweaning growth rate of Lama2 ${ }^{-/-}$mice was significantly increased by inactivation of Bax, through growth of $\mathrm{Lama2}^{-1-} \mathrm{Bax} \mathrm{x}^{-1-}$ mice lagged behind that of healthy Lama2 $^{+/+}$wild-type mice. Error bars $=\mathrm{SE} ; n=5-15$. The mean body weights of $\mathrm{Lama2}^{-1-} \mathrm{Bax}^{-/-}$and $\mathrm{Lama2}^{-/-} \mathrm{Bax}^{+/+}$mice were significantly different from each other with $P<0.04$ at days 28 and 35 and $P<0.01$ at days 42 and 49.

expressed in normal adult skeletal muscle (9) (Figure 2B). Expression of human $\mathrm{Bcl}-2$ by the $p M y o D-h B c l-2$ transgene was restricted to skeletal muscle and not observed in other tissues (Figure $2 \mathrm{~B}$ ). When introduced into Lama2 ${ }^{-/-}$mice by crossbreeding, this $p M y o D-h B c l-2$ transgene increased lifespan, because all the transgenic mice $(n=6)$ lived longer than 90 days. Of these 6 transgenic Lama2 ${ }^{-/-}$mice, we noted deaths at 94,132, and 147 days, with 3 remaining alive at 120 days as of this writing. The lifespan of transgenic mice was thus much longer than that of nontransgenic Lama2 ${ }^{--}$mice. The $p M y o D-h B c l-2$ transgene also increased the growth rate of Lama2 ${ }^{-/-}$mice. At 4-4.5 weeks of age, male Lama2 ${ }^{--}$mice with the $p M y o D-h B c l-2$ transgene weighed $10.2 \pm 2.5 \mathrm{~g}$ (average $\pm \mathrm{SD}, n=9$ ), whereas those without the transgene weighed significantly less at $6.3 \pm 2.3 \mathrm{~g}(n=7, P<0.01$ by $t$ test). The ability of the transgene to increase survival and growth of Lama2 ${ }^{-/-}$mice shows that skeletal muscle-specific alteration of $\mathrm{Bcl}-2$ is sufficient to ameliorate pathology due to laminin- $\alpha 2$ deficiency.

Bax inactivation, but not muscle-specific expression of Bcl-2, also decreased fixed contractures of the hind limbs in Lama2 ${ }^{-1-}$ mice. In addition to skeletal muscle defects, most Lama2 ${ }^{-/-}$mice develop fixed contractures (i.e., permanent locking into an extended position) of the hind limbs by 6-8 weeks after birth (Figure 1B), apparently due
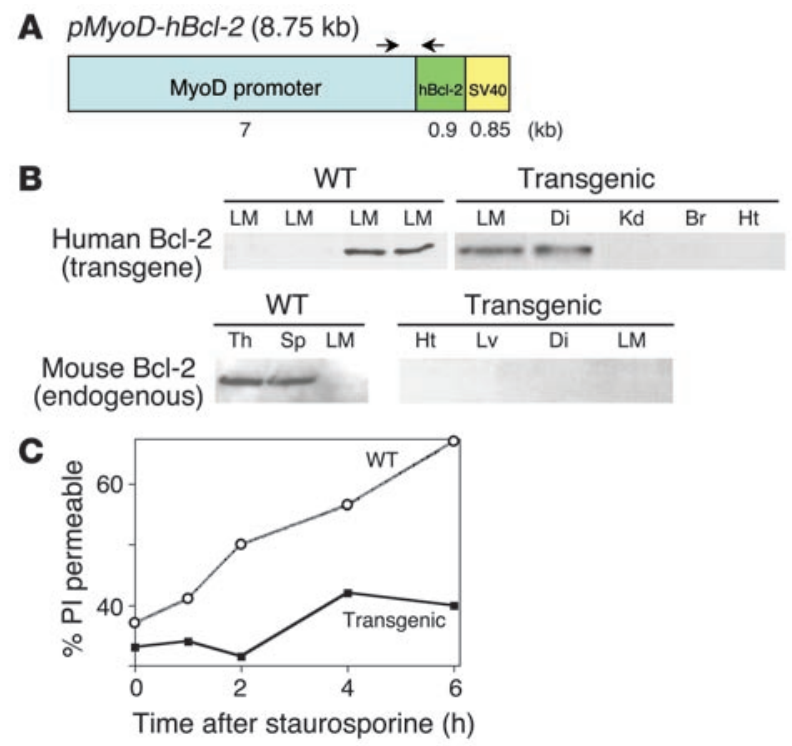
A
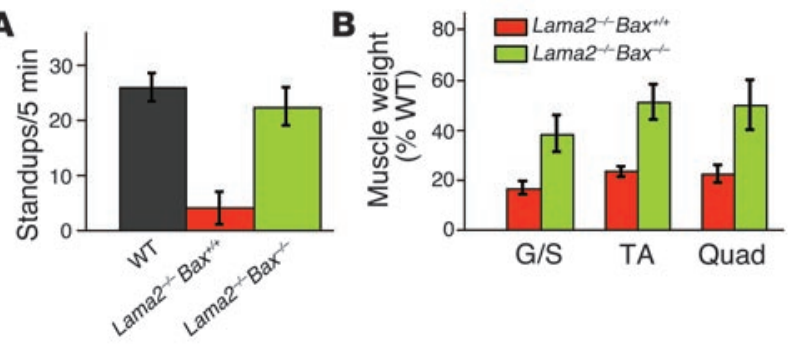

C

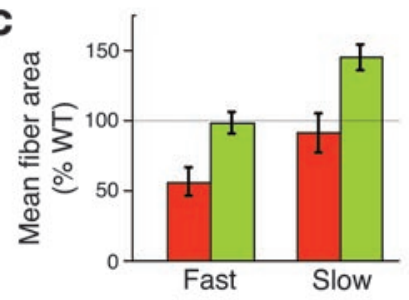

Figure 3

Inactivation of Bax improved Lama2-/- muscles. (A) Exploratory behavior, measured by the number of times mice stood up on their hind legs during the first 5 minutes in a new cage, was much decreased in 6-week-old Lama2-/-Bax ${ }^{+/+}$mice (red bar), compared with wild-type Lama2 ${ }^{+/+} \mathrm{Bax}^{+/+}$mice (WT, black bar). When Bax was inactivated in Lama2 ${ }^{-/-}$mice, in contrast, the Lama2 ${ }^{--} B \mathrm{Bax}^{-/}$mice (green bar) showed exploratory behavior that was near that of wild-type. Error bars $=\mathrm{SE}$; $n=3$ for $\mathrm{Lama2}^{-/-} \mathrm{Bax}^{+/+}$mice and $n=4$ for WT and Lama2 ${ }^{-/-} \mathrm{Bax}^{-/-}$mice. (B) The mass of individual Lama2 ${ }^{-/-}$muscles was increased by inactivation of Bax. The gastrocnemius/soleus (G/S), tibialis anterior (TA), and quadriceps (Quad) muscles weighed more in $\mathrm{Lama2}^{-/-} \mathrm{Bax}^{-/-}$mice (green bars) than in $\mathrm{Lama2}^{-/-} \mathrm{Bax}^{+/+}$mice (red bars). Data are plotted as percentage of wild-type (Lama2-positive, Bax-positive) values. Error bars $=$ SE; $n=3-11$. (C) The size of myofibers in Lama2 ${ }^{-1-}$ muscles was increased by inactivation of Bax. In the soleus muscle, both fast and slow myofibers had larger mean cross-sectional areas in Lama2 ${ }^{-/-}$ $\mathrm{Bax}^{-/-}$mice (green bars) than in Lama2 ${ }^{-1-} \mathrm{Bax}^{+/+}$mice (red bars). Data are plotted as percentage of wild-type (Lama2-positive, Bax-positive) values. Error bars = SE; $n=3-5$. In all panels, the Bax-positive and Bax-null samples were significantly different at $P<0.05$ ( $t$ test using primary data prior to conversion to percentage of wild-type).

to failure of basal lamina formation by Schwann cells and subsequent conduction defects in motor nerves $(2,5,7,10)$. Fixed contractures and paralysis are not prevented by muscle-specific expression of laminin- $\alpha 2$ (7). We also observed development of hind limb contractures in Lama2 $->$ mice that had normal Bax expression, even if they also carried the muscle-specific Bcl-2 transgene. In marked contrast, we did not observe fixed contractures of the hind limbs in Lama2 $2^{-/-}$mice that lacked Bax (Figure 1B). Even up to 6 months of age, the hind limbs in Bax-null mice, though appearing much weaker than wild-type, were not paralyzed. Thus, inactivation of Bax expression, which is normally widespread in both muscle and nonmuscle tissues (11), appeared to ameliorate functional defect motor nerves, as well as skeletal muscles, of Lama2 $2^{-/}$mice.

Inactivation of Bax also increased the spontaneous standing movements of Lama2 $2^{-/}$mice, which is further evidence of improved hind limb function. When placed in a new cage, normal mice showed exploratory behavior, including repeated standing up on hind limbs. As early as $4-5$ weeks after birth, we found that Lama2 $2^{-/}$mice stood up less than $25 \%$ as often as normal mice, consistent with impaired ability of the hind limbs to function in weight-bearing activity. This spontaneous standing behavior was increased to near the level found in normal mice, however, when the Lama2 $2^{-/}$mice were made Bax-null (Figure 3A).

Individual muscles in $\mathrm{Lama2}^{-/-}$mice that were also Bax null were bigger and had larger and more myofibers than did muscles in Lama $2^{-/}$mice that were Bax positive (Figure 3, B and C, and Figure 4). Compared with the healthy muscles in $\mathrm{Lama2}^{+/+}$mice, the diseased muscles in Lama2 $2^{--}$mice were much smaller. When the Lama2 $->$ mice were made Bax-null, however, the weights of individual muscles (e.g., gastrocnemius/soleus complex, tibialis anterior, quadriceps) were increased (Figure 3B). The cross-sectional areas of the muscles also increased; for example, in the soleus muscle (Figure 4) the mean cross-sectional area ( \pm SE) of the muscle was $0.47 \pm 0.04 \mathrm{~mm}^{2}(n=3)$ in $\mathrm{Lama2}^{-/-}$Bax ${ }^{+/+}$mice but was increased to $1.14 \pm 0.15 \mathrm{~mm}^{2}(n=3)$ in Lama2 $2^{-/-B a x-/-}$ mice (a significant difference at $P=0.013$ by the $t$ test). In wild-type mice, the cross-sectional area of the soleus was $1.71 \pm 0.16 \mathrm{~mm}^{2}(n=6)$. The mean cross-sectional areas of both fast and slow myofibers were also significantly increased when the Lama2 ${ }^{--}$mice were made Bax-null (Figure 3C). In addition, the number of myofibers in a muscle was increased when the Lama2 $2^{-/-}$mice were made Bax-null. In the soleus muscle, for example, the mean number $( \pm$ SE) of myofibers was $336 \pm 29$ $(n=3)$ in Lama2 $2^{-/-B a x}{ }^{+/}$mice, but was increased to $462 \pm 3.1(n=3)$ in Lama2 $2^{-/-B a x}{ }^{-/}$mice, a significant difference at $P=0.012$ by the $t$ test. In wild-type mice, the mean number of myofibers in the soleus was $991 \pm 40(n=6)$. Thus, the improvements in Lama2 ${ }^{--}$muscles produced by inactivation of Bax, though significant, were partial as muscle properties generally remained below normal.
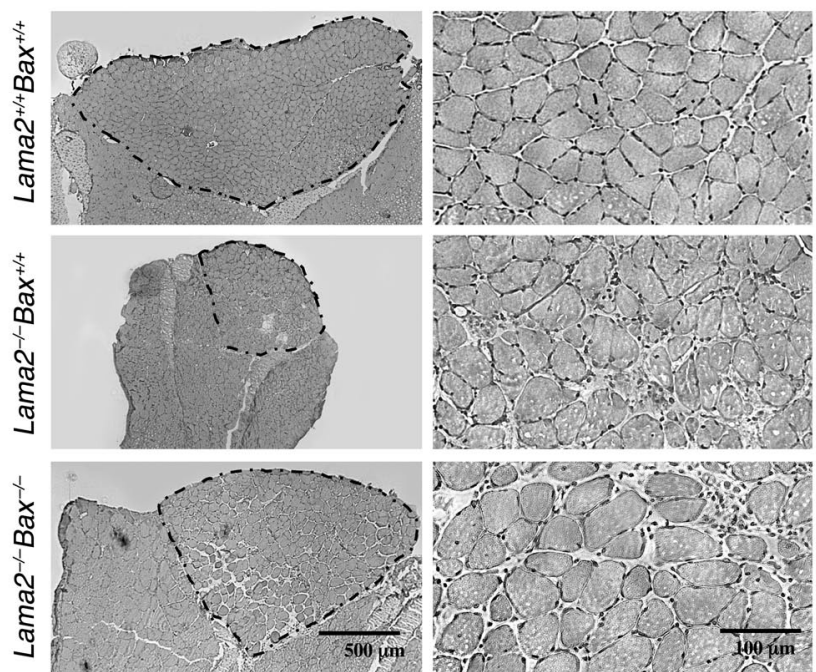

\section{Figure 4}

Inactivation of Bax improved soleus muscle histology. Frozen sections were prepared from the leg muscles of 7-week-old mice of different genotypes, including wild-type mice (Lama2 ${ }^{+/+} \mathrm{Bax}^{+/+}$, top row), laminin$\alpha 2-$ deficient mice with normal Bax ( $\mathrm{Lama}^{-/-} \mathrm{Bax}^{+/+}$, central row), and laminin- $\alpha 2-$ deficient mice with no Bax (Lama2 ${ }^{-1-} \mathrm{Bax}^{-1-}$, bottom row) as indicated. After staining with $\mathrm{H} \& \mathrm{E}$, sections were examined at low (left column) and high (right column) magnification. In the left column, the soleus muscles are outlined to show that inactivation of Bax increased the overall size of the $\mathrm{Lama2}^{-/-}$soleus muscle, and the right column shows that inactivation of Bax also increased the cross-sectional areas of myofibers in Lama2 $2^{--}$soleus muscle (see text and Figure 3 for quantitative measurements). Irrespective of Bax genotype, Lama2 $2^{-1-}$ soleus muscles had about the same number of mononucleate cells and myofibers with central nuclei. Scale bars: left column, $500 \mu \mathrm{m}$; right column, $100 \mu \mathrm{m}$. 
These improvements in muscle properties upon Bax inactivation were not due to an effect on myofiber formation during development, because when normal $\mathrm{Lama2}^{+/+}$mice are made Bax-null, there is no change in the number of myofibers per muscle and myofibers are somewhat smaller than in Bax-positive, Lama2-positive mice (8). The improved muscle properties also did not appear to be due to correction of the altered membrane protein composition found in Lama2 $2^{-/-}$mice. For example, we found by Western blotting that the elevation (increased approximately 3 times) of $\beta$-dystroglycan seen in Lama2 ${ }^{-/-}$, compared with wild-type muscles (12), was not corrected by Bax inactivation (not shown).

Regeneration in Lama2 $2^{-/-}$muscles, as measured by myofibers with central nuclei, also did not appear to be altered by inactivation of Bax. Despite significant myopathology, Lama2 ${ }^{-1-}$ muscles at $5-8$ weeks of age show relatively poor regeneration $(13,14)$. Newly regenerated myofibers, which have their nuclei located in the center of the fiber rather than at the periphery, amounted to approximately $20 \%$ of the total Lama2 $2^{-/}$myofibers in the soleus and other muscles $(13,14)$. (For comparison, muscles in dystrophin-deficient $m d x$ mice show high levels of regeneration with greater than $90 \%$ of myofibers reported to have central nuclei by 24 weeks of age; see ref. 13.) Inactivation of Bax failed to produce any consistent difference in the percentages of myofibers with central nuclei in Lama2-/- muscles (not shown).

Satellite cell numbers also appeared to be unaffected by inactivation of Bax or expression of the transgene. We examined satellite cells in Lama2 $2^{-/}$muscles because both Bax and the MyoD transgene were expressed in proliferating satellite cells, as well as in skeletal muscle cells beginning near the time myofibers first form in embryonic development, and in all multinucleate myofibers in the adult (15, 16) (Figure 2B and data not shown). Nonetheless, neither inactivation of Bax nor expression of the $\mathrm{Bcl}-2$ transgene appeared to affect the number of satellite cells in Lama2 $2^{-1-}$ muscles, as determined either by counting mononucleate cells found in cross-sections of Lama2 $2^{-/}$muscles or by determining the number of satellite cells that could be successfully cultured per gram of muscle wet weight (data not shown). On the other hand, both Bax inactivation and expression of the $\mathrm{Bcl}-2$ transgene inhibit experimentally induced cell death of both myoblasts and myotubes in culture (8) (Figure 2C, and data not shown).

\section{Discussion}

Because Lama2 $2^{-/}$pathology was ameliorated by 2 genetic interventions, inactivation of $\mathrm{Bax}$ and overexpression of $\mathrm{Bcl}-2$, that were designed to inhibit apoptosis, it appears that apoptosis plays a significant role in disease progression in Lama2 $2^{-/-}$mice. Taken together, our analyses suggest that Bax inactivation does not lessen myopathology in Lama2 $2^{-/-}$mice by improving the success of regeneration, but rather by increasing the postnatal survival of myofibers that had formed during earlier stages of muscle development. In skeletal muscle, the heterotrimeric laminins 2 and 4, which include laminin- $\alpha 2$ as a subunit, interact both with basal lamina components and with the cell surface proteins $\alpha$-dystroglycan and integrin $\alpha 7 / \beta 1$ (2). One consequence of the loss of laminin- $\alpha 2$, therefore, is myofiber dysfunction due to disrupted cross-linking of the plasma membrane and basal lamina (17). A second consequence of the loss of laminin- $\alpha 2$, however, could be disrupted integrin and dystroglycan signaling, which might lead to apoptosis.

Previous studies showed that muscle, but not motor nerve, pathology in Lama2 ${ }^{-/-}$mice can be prevented by muscle-specific expression of either laminin- $\alpha 2$ or a modified agrin protein that can replace laminin $(7,12)$. In those studies, restoration of laminin function likely both restored muscle function and eliminated apoptosis in muscle cells. Partial amelioration of 1 or more aspects of laminin- $\alpha 2$ deficiency in mice can also be produced by feeding a $50 \%$ protein diet, inactivating the complement system, or by administering IGF-1, clenbuterol, or prednisolone (18-21). Whether these treatments reduce pathology through inhibition of apoptosis remains to be determined.

Our study demonstrates that disease due to loss of laminin- $\alpha 2$ can be significantly ameliorated by interventions designed to inhibit apoptosis. Of particular significance is that inactivation of Bax, which is normally widely expressed, appears to ameliorate both muscle and motor nerve pathology, though neither is completely corrected. An important remaining question is whether antiapoptotic therapies will remain effective if started later in life after onset of disease. Genetic and pharmacological treatments designed to inhibit apoptosis also produce a moderate (10-20\%) increase of lifespan in a mouse model of familial amyotrophic lateral sclerosis (22-24). Furthermore, treatment with cyclosporin A inhibits mitochondria-mediated apoptosis and improves muscle histology in collagen VI-deficient mice (25). On the other hand, overexpression of an apoptosis-inhibiting protein in dystrophindeficient $m d x$ mouse muscles does not appear to ameliorate pathology (26). Thus, apoptosis is more important to pathogenesis in some neuromuscular diseases than in others, and apoptosis appears to play a particularly large role in laminin- $\alpha 2$ deficiency.

In Lama2 ${ }^{-/-}$mice, it is possible that more stringent inhibition of apoptosis, perhaps by higher expression of $\mathrm{Bcl}-2$, or additional antiapoptotic factors, or by inactivation of additional proapoptosis Bcl-2 family members, might further reduce pathology beyond what was seen here. Antiapoptosis therapies based on genetic interventions using agents such as RNA-mediated interface (RNAi) or viral vectors might prove applicable to humans. Pharmacological inhibitors of apoptosis such as caspase inhibitors should also be considered as candidates to ameliorate Lama2-/- disease. An antiapoptosis therapy that significantly slows disease progression in human CMD1A could be of considerable benefit.

\section{Methods}

Mice. Heterozygous B6.129 Lama $2^{d y-W /+}$ mice, which carried the targeted $d y-W$ mutation in the Lama2 gene (7), were a gift of Eva Engvall (Burnham Institute, La Jolla, California, USA). Heterozygous C57BL/6-Bax ${ }^{t m 1 S j k}$ mice with a targeted mutation in the Bax gene (27) were obtained from The Jackson Laboratory. For ectopic expression of Bcl-2 in muscle cells, we prepared transgenic mice in which an approximately $7-\mathrm{kb}$ fragment of the mouse MyoD promoter (28) directed expression of the full-length human Bcl-2 cDNA (from American Type Culture Collection) (Figure 2A). The transgene is named $p M y o D-h B c l-2$ and was maintained in $C 57 \mathrm{BL} / 6 \mathrm{~J}$ mice. Littermates were used as controls in all experiments.

Western blotting and immunohistochemistry with the human Bcl-2specific mAbs 6C8 (BD Biosciences - Pharmingen) or Ab-1 (Oncogene Research Products) was used to confirm that the transgenes were expressed only in skeletal muscle and that the transgenes were expressed in all myofibers (Figure 2B and J.A. Dominov, unpublished observation). Endogenous mouse $\mathrm{Bcl}-2$ was detected with the mouse $\mathrm{Bcl}-2$-specific mAb 3F11 (BD Biosciences - Pharmingen).

To produce Lama2 $2^{-/-}$mice with the appropriate Bax or transgenic genotypes for these studies, Lama2 ${ }^{+/-}$heterozygotes were first crossbred with either $B a x^{+/-}$heterozygotes or with mice carrying the $p M y o D-h B c l-2$ 
transgene. Double heterozygotes among the progeny of this first breeding were then crossbred, and the progeny were genotyped at weaning (approximately 3 weeks of age) using PCR-based assays of tail DNA to identify Lama2 $2^{-/-}$progeny that carried the desired Bax or transgenic genotypes, as well as littermates to serve as controls. Observations of the effects of Bax and transgene genotypes on survival of Lama2 $2^{-/-}$mice began at weaning when genotypes were determined (Figure 1A).

Mice were observed daily, and weights were measured once or twice per week. Mice were sacrificed if pathology increased to a point where movement was severely impaired and death appeared imminent. Functional capabilities of mice were assayed by determining the number of times that mice stood up on their hind limbs during their first five minutes of exploratory motion after being placed in a new cage. Protocols for experiments with mice were approved by the Institutional Animal Use and Care Committee of Boston Biomedical Research Institute and overseen by a veterinarian.

Histology and cell culture. Individual muscles were dissected, frozen immediately in 2-methylbutane chilled by liquid nitrogen, and 10- $\mu \mathrm{m}$ cryostat sections prepared from matching regions of muscles for comparison of different genotypes. Sections were stained with H\&E. Cross-sectional areas of individual myofibers were determined using the NIH Image program. Myofibers with centrally located nuclei and total numbers of myofibers were counted manually. ATPase histochemistry (8) was used to identify fast and slow myofibers. For each measurement, muscle sections were prepared from the largest region of each muscle, and myofibers were measured and enumerated in multiple adjacent $\times 10$ or $\times 20$ microscope fields until the entire area of each muscle section was analyzed. Statistical significance was assessed by the appropriate $\chi^{2}$ test, unpaired 2 -tailed $t$ test, Welch alternate $t$ test, or nonparametric Mann-Whitney test using the InStat computer program (v2.03; GraphPad Software Inc.). For cell cultures, mononucleate cells were isolated from dissected muscles, enriched for satellite cells by density centrif- ugation, and cultured as in our previous work $(8,15)$. To assay experimentally induced apoptosis, cell cultures were treated with $100 \mathrm{nM}$ staurosporine to induce apoptosis, and cells that died in response to staurosporine treatment were identified based on permeability to $5 \mu \mathrm{g} / \mathrm{ml}$ propidium iodide.

\section{Acknowledgments}

This work was supported by a grant to J. Dominov from the NIH (National Institute of Arthritis and Musculoskeletal and Skin Diseases [NIAMS]) and by grants to J.B. Miller from the Muscular Dystrophy Association of the USA, the NIH (National Heart, Lung, and Blood Institute [NHLBI], NIAMS, National Institute of Environmental Health Sciences [NIEHS]), and the US Department of Agriculture. We thank Eva Engvall for providing Lama2 $2^{+/-}$mice; Stephen Tapscott (Fred Hutchinson Cancer Research Center, Seattle, Washington, USA) for the MyoD promoter fragment; Rick Boyce for helpful conversations; and Katie Archer, Magdalena Ardelt, Mary Lou Beermann, Amanda J. Kravetz, and Clifford J. Swap for technical analyses. J.B. Miller thanks Frank Stockdale and Ralph Yount.

Received for publication August 4, 2004, and accepted in revised form September 15, 2004.

Address correspondence to: Jeffrey Boone Miller, Boston Biomedical Research Institute, 64 Grove Street, Watertown, Massachusetts 02478, USA. Phone: (617) 658-7737; Fax: (617) 972-1761; E-mail: miller@bbri.org.

Mahasweta Girgenrath and Janice A. Dominov contributed equally to this work.
1. Khurana, T.S., and Davies, K.E. 2003. Pharmacological strategies for muscular dystrophy. Nat. Rev. Drug Discov. 2:379-390.

2. Miyagoe-Suzuki, Y., Nakagawa, M., and Takeda, I. 2000. Merosin and congenital muscular dystrophy. Microsc. Res. Tech. 48:181-191.

3. Allamand, V., and Guicheney, P. 2002. Merosin-deficient congenital muscular dystrophy, autosomal recessive (MDC1A, MIM\#156225, LAMA2 gene coding for alpha2 chain of laminin). Eur. J. Hum. Genet. 10:91-94.

4. Hayashi, Y.K., et al. 2001. Massive muscle cell degeneration in the early stage of merosin-deficient congenital muscular dystrophy. Neuromuscul. Disord. 11:350-359.

5. Miyagoe, Y., et al. 1997. Laminin alpha2 chain-null mutant mice by targeted disruption of the Lama2 gene: a new model of merosin (laminin 2)-deficient congenital muscular dystrophy. FEBS Lett. 415:33-39.

6. Mukasa, T., Momoi, T., and Momoi, M.Y. 1999 Activation of caspase-3 apoptotic pathways in skeletal muscle fibers in laminin alpha2-deficient mice. Biochem. Biophys. Res. Commun. 260:139-142.

7. Kuang, W., et al. 1999. Merosin-deficient congenital muscular dystrophy: partial genetic correction in two mouse models. J. Clin. Invest. 102:844-852.

8. Nowak, J.A., et al. 2004. Immortalization of myogenic cells can occur without loss of $\mathrm{p} 16^{\text {INK4a, }}$ $\mathrm{p} 19^{A R F}$, or $\mathrm{p} 53$ and is accelerated by inactivation of Bax. BMC Cell Biol. 5:1.

9. Krajewski, S., et al. 1995. Immunohistochemical analysis of Mcl-1 protein in human tissues. Differential regulation of $\mathrm{Mcl}-1$ and $\mathrm{Bcl}-2$ protein production suggests a unique role for Mcl- 1 in control of programmed cell death in vivo. Am. J. Pathol. 146:1309-1319.

10. Nakagawa, M., et al. 2001. Schwann cell myelina- tion occurred without basal lamina formation in laminin alpha2 chain-null mutant (dy3K/dy3K) mice. Glia. 35:101-110.

11. Krajewski, S., et al. 1994. Immunohistochemical determination of in vivo distribution of Bax, a dominant inhibitor of Bcl-2. Am. J. Pathol. 145:1323-1336.

12. Moll, J., et al. 2001. An agrin minigene rescues dystrophic symptoms in a mouse model for congenital muscular dystrophy. Nature. 413:302-307.

13. Connolly, A.M., Keeling, R.M., Mehta, S., Pestronk, A., and Sanes, J.R. 2001. Three mouse models of muscular dystrophy: the natural history of strength and fatigue in dystrophin-, dystrophin/utrophin-, and laminin alpha2-deficient mice. Neuromuscul. Disord. 11:703-712.

14. Kuang, W., Xu, H., Vilquin, J.T., and Engvall, E. 1999. Activation of the Lama2 gene in muscle regeneration: abortive regeneration in laminin alpha2-deficiency. Lab. Invest. 79:1601-1613.

15. Dominov, J.A., Houlihan-Kawamoto, C.A., Swap, C.J., and Miller, J.B. 2001. Pro- and anti-apoptotic members of the Bcl-2 family in skeletal muscle: a distinct role for $\mathrm{Bcl}-2$ in later stages of myogenesis. Dev. Dyn. 220:18-26.

16. Asakura, A., Lyons, G.E., and Tapscott, S.J. 1995. The regulation of MyoD gene expression: conserved elements mediate expression in embryonic axial muscle. Dev. Biol. 171:386-398.

17. Jannapureddy, S.R., Patel, N.D., Hwang, W., and Boriek, A.M. 2003. Merosin deficiency leads to alterations in passive and active skeletal muscle mechanics. J. Appl. Physiol. 94:2524-2533.

18. Zdanowicz, M.M., et al. 1995. High protein diet has beneficial effects in murine muscular dystrophy. J. Nutr. 125:1150-1158.

19. Hayes, A., and Williams, D.A. 1998. Examining potential drug therapies for muscular dystrophy utilising the dy/dy mouse: I. Clenbuterol. J. Neurol. Sci. 157:122-128.

20. Lynch, G.S., Cuffe, S.A., Plant, D.R., and Gregorevic, P. 2001. IGF-I treatment improves the functional properties of fast- and slow-twitch skeletal muscles from dystrophic mice. Neuromuscul. Disord. 11:260-268.

21. Connolly, A.M., Keeling, R.M., Streif, E.M. Pestronk, A., and Mehta, S. 2002. Complement 3 deficiency and oral prednisolone improve strength and prolong survival of laminin alpha2-deficient mice. J. Neuroimmunol. 127:80-87.

22. Kostic, V., Jackson-Lewis, V., de Bilbao, F., DuboisDauphin, M., and Przedborski, S. 1997. Bcl-2: prolonging life in a transgenic mouse model of familial amyotrophic lateral sclerosis. Science. 277:559-562.

23. Friedlander, R.M., Brown, R.H., Gagliardini, V., Wang, J., and Yuan, J. 1997. Inhibition of ICE slows ALS in mice. Nature. 388:31.

24. Zhu, S., et al. 2002. Minocycline inhibits cytochrome $c$ release and delays progression of amyotrophic lateral sclerosis in mice. Nature. 417:74-78.

25. Abmayr, S., Crawford, R.W., and Chamberlain, J.S 2004. Characterization of ARC, apoptosis repressor interacting with CARD, in normal and dystrophin-deficient skeletal muscle. Hum. Mol. Genet. 13:213-221.

26. Irwin, W.A., et al. 2003. Mitochondrial dysfunction and apoptosis in myopathic mice with collagen VI deficiency. Nat. Genet. 35:367-371.

27. Knudson, C.M., Tung, K.S., Tourtellotte, W.G., Brown, G.A., and Korsmeyer, S.J. 1995. Bax-deficient mice with lymphoid hyperplasia and male germ cell death. Science. 270:96-99.

28. Tapscott, S.J., Lassar, A.B., and Weintraub, H.A. 1992. Novel myoblast enhancer element mediates MyoD transcription. Mol. Cell. Biol. 12:4994-5003. 